\title{
Asuntomessuja toteutettu 50 vuotta!
}

Erkki Kuoppamäki

\section{Tausta ja messuidea}

Yhdyskuntarakenteen muutos oli 196o-luvun puolivälissä Suomessa kiihkeää. Sen hallitsemiseksi ratkaisuja etsittiin monien komiteoiden työllä ja tulosten pohjalta tehtyjen lakien sekä Asuntohallituksen perustamisen avulla. Tunnettu ja toteutunut tavoite oli puolen miljoonan asunnon rakentaminen kymmenvuotiskaudella 1966-75. Se tapahtui pitkälti aluerakentamisena kerrostaloja suosien.

Pientaloilla ja etenkin omakotitaloilla oli kuitenkin asukkaitten vahva kannatus, joten kysynnän sekä tarjonnan epäsuhta oli ilmeinen. Vuonna 1964 perustetussa Suomen Asuntoliitossa reagoitiin tähän luomalla pientalojen näyttelytoimintaa harjoittava organisaatio Asuntomessuosuuskunta - Bostadsmässa Andelslaget, joka merkittiin kaupparekisteriin 10.6.1966. Toimintaidea oli rakentaa asuntoalue, esitellä se yleisölle ja näyttelyajan jälkeen luovuttaa se asukkaille.

Tuolloin nähtiin tulevalle toiminnalle keskeiseksi vahva rahoituspohja, jonka vuoksi ensiksi varmistettiin Asuntohallituksen kiinnostus ja vahva henkilöedustus osuuskunnan hallituksessa. Näin syntyi suopeutta messuasuntojen aravarahoituksen varaamiseen. Sen jälkeen mukaan saatiin osuuskunnan jäseniksi pankkijärjestöt ja niistä edustajat myös osuuskunnan hallitukseen. Siten saatiin linkki pankkeihin messukohteen primäärilainoitukseen, joka oli usein vaikeuksissa pankkien pitäessä yritysten luototusta tärkeämpänä ja tuottoisampana. Jäseneksi kutsuttiin myös Asuntoreformiyhdistys ja Suomen 
Messusäätiö. Myöhemmin jäseniksi tulivat myös kuntaliitot Suomen Kaupunkiliitto ja Kuntaliitto.

Messutoteutus edellytti asiasta kiinnostuneita isäntäkuntia ja niitähän ilmaantui. Kun rahoitusta löytyi, ei tarvinnut pitkään neuvotella, ja pian kuntia oli pieneksi jonoksi asti. Messurytmiäkin tihennettiin alun biennaalista vuosittaiseksi. Välillä järjestettiin jopa useampi messutapahtuma yhtäaikaisesti samana kesänä!

Käytännön yhteistyössä kunta vastaa kaavan ja kunnallistekniikan valmistumisesta ja messupysäköinnistä, osuuskunta messujen järjestämisestä ja markkinoinnista. Messut on aina toteutettu kunnan hallitsemalle maalle ja varmistettu riittävä asuntokysyntä.

Lisäksi muun muassa toistuvilla arkkitehti- ja tarjouskilpailuilla on messuille pyritty saamaan ja kehittämään laadukkaita ja kiinnostavia toteutuksia. Messurakentajien kiinnostus on luonnollisesti vaihdellut. Joissakin tapauksissa kunta on jarruttanut muiden kilpailevien alueiden avaamista kysynnän varmistamiseksi.

\section{Messualueitten kaavoituksesta ja kunnallistekniikasta}

Alkuvuosina aina vuoteen 1977 messujen painopiste oli enemmän tai vähemmän hankkeitten ja messujärjestelyjen puolella. Kaavat edustivat aikansa ruutukaava-ajattelua ja painottivat asumisen yksityisyyttä. Moni messualue sijoittui peltomaastoon. Virkistävinä poikkeamina voi pitää vuoden 1974 Keravan ja vuoden 1975 Kokkolan messujen rakentamisen ryhmittelyä neljän korttelipihan ympärille, kaiketi yhteisöllisyyttä mahdollistamaan.

Vantaan 1977 messuilla puolestaan keskeinen puisto halkaisee alueen, ja maininnan saa vahva panostus peltomaiseman muuttamiseksi vehreäksi asuinympäristöksi. Alueelle istutettiin noin 900 puuta ja yli 6000 pensasta ja kaava velvoitti näkösuojatun ulko-oleskelutilan rakentamisen jokaisen asunnon yhteyteen.

Ensimmäiset "orgaaniset" kaavat tehtiin Mynämäelle 1977 ja Lahteen 1978, joissa jo maaston vaihtelevuus puolsi ruutu-ajattelusta irtautumista. Joutsenossa 1979 puolestaan tasamaalla asuntokatujen harkitulla taitoksella muodostettiin pikku aukiot tai "torit", joille rakentuivat ensimmäiset julkisen tilan "public design"-esimerkit.

Ensimmäiset messukaavat arkkitehtikilpailun kautta syntyivät Lahden 1978 ja Kuopion 1980 messuille. Jyväskylän 1985 messualue oli osa Kuokkalan kaavakilpailun aluetta. Sitten tuli lähes vuosittainen suma: yhteensä kahdeksan peräkkäistä kaavakilpailua. Muista poikkeavana maininnan ansaitsee Tampereen messualueeksi valittu, aikanaan 1920-luvulla rakennettu Puu-Tammela. 
Osana keskusta-aluetta Puu-Tammela oli ollut pitkään kiistelyn kohteena; korjatako vai esimerkiksi purkaa koulujen alueeksi, kuten kaavakin välillä edellytti. Pattitilannetta yritti Reima Pietiläkin turhaan ratkoa. Kaupungin ja Asuntomessujen järjestämä aatekilpailu ilman ennakkoehtoa purkamisen, korjauksen tai rakentamisen suhteista ja saadut 42 erilaista ehdotusta loivat yhteisen näkemyksen. Alueelle laadittiin ja vahvistui asuntokäyttöä korostava asemakaava ja messut pidettiin 1990.

Omarantaisten tonttien kaavoitustabu puolestaan murtui Varkaudessa 1991. Se tapahtui toisaalta yleisen arkkitehtikilpailun ohjelmoinnin ja tuloksen myötä; toisaalta siksi, että Varkaudessa on rantametrejä tarpeeksi vaikka jokaiselle perheelle.

Kunnallistekniikka on säännönmukaisesti rakennettu messuille valmiiksi ja monesti yleistasoa selvästi tasokkaammin. Tämä on tehty messuyleisöä varten, mutta myös ja ennen kaikkea lisäämään yritysten ja omakotirakentajien kiinnostusta mukaantuloon.

Linja on palkittu myös erilaisin tunnustuksin sekä yleisön ja asukkaitten arvioin. Esimerkkinä voidaan mainita Joensuun 1995 kanavatoteutus siltoineen, joka sai kunniamaininnan saman vuoden ympäristörakennekilpailussa. Myös kansainvälistä tunnustusta tuli. EU:n vammaisohjelman Helios-palkinto myönnettiin alueen ja talojen toteuttamisesta esteettöminä ja aluetta esitteltiin "maailman ensimmäisenä" useissa konferensseissa.

Ylöjärven vuoden 1996 messualueen Kotitanhua-pihakatu puolestaan valittiin vuoden 1997 ympäristörakenteeksi "valaistuksineen ja kiveyksineen ihmisläheisenä julkisena tilana uuden pientaloalueen keskellä". Todettakoon, että pihakatuja esiintyi messuilla jo ennen sitä koskevaa liikennemerkkiasetusta Forssassa 1982 ja "oikeana" pihakatuna Jyväskylässä 1985 sekä hidaskatuversiona Imatralla 1986.

Varsinaisen tekniikan osalta uutuuksia olivat muun muassa Keravan 1974 yhteisantenniverkosto, Imatran 1986 maakaasun pienjakeluverkko, Varkauden 1991 laajakaistaverkko ja vielä esimerkiksi Pietarsaaren 1994 messuilla alueen läheisen teollisuuden vedenpuhdistamon hukkalämpöä messutaloihin siirtävä järeä lämpöpumppuratkaisu ja asuntokatujen niin sanottu muoviasfaltti sekä Ylöjärven 1996 kaksivesijärjestelmä.

Puisto- ja viherrakentamisesta Vantaan 1977 lisäksi mainittakoon myös Lahden 1978 puisto- ja viherrakentaminen keinolampineen hyvän pientaloympäristön osana. Jyväskylässä 1985 kaupunki suunnitteli ja rakensi keskeisen perhepuiston, jonne toteutettiin myös asukkaille monitoimitalo. Torniossa 1987 oli teemana pohjoisen luonnon olosuhteiden huomioiminen. Sen pohjalta 
rakennetussa Arboretum-puistossa on edelleen nähtävänä yli 300 pohjoisilla alueilla viihtyvää kasvilajiketta.

Julkisen tilan ulkokalusteiden osalta jo edellä todettiin Joutsenon 1979 katuaukiot ja katukalusteet. Siellä näyttävin esimerkki on Tiilikeskuksen toteuttama "Tiilitori". Muina toteutuksina mainittakoon Tornion 1987 messuteemanakin ollut kaupunkitilan kalusteiden kehittäminen tuotesuunnittelukilpailun avulla. Aivan erillinen yksittäinen hanke on ollut Espoon Tapiolaan Asuntomessujen ja kaupungin yhteisesti järjestämä Public Design -näyttely kesällä 1992. Se lienee Suomen ensimmäinen lajissaan.

Messurakentamisessa aluksi vahva pientalopainotus Asukaskyselyissä pientalot ja niistä etenkin omakotitalot olivat monille haave. Sen toteutumiseksi asuntomessuilla alkuvuosina 1970-79 messuasunnoista noin 90\% tuli pientaloihin. Vastaavasti aravaomakotimäärät kasvoivat, sillä kun vuonna 1970 rakennettiin niitä koko Suomessa hieman yli 2000 kappaletta, niin vuonna 1979 jo noin 8000 kappaletta. Alkuvuosina vain Vaasan 1975 ja Oulun 1976 messuilla oli myös kerrostaloja, nekin pienkerrostaloasuntoja. Jatkossakin vuoteen 2000 saakka lähinnä keskuskaupunkien messukohteissa (Jyväskylä, Turku, Tampere, Joensuu) oli "kunnon hissitaloja".

Omakotitalojen osalta maassa oli totuttu vanhastaan melko väljään rakentamiseen tonttikoon ollessa tyypillisesti $1000-2000 \mathrm{~m}^{2}$, jolla sijaitsi"punainen tupa ja perunamaa". Tuusulan 1970 messualueella jo tonttien keskikoko on noin $700 \mathrm{~m}^{2}$. Myöhemmin vielä kaupunkimaisempaa asumista hakien tonttikoko pieneni joissain kohteissa edelleen.

Vantaalla 1977 keskikoko on $300 \mathrm{~m}^{2}$ ja tonttitehokkuus o,28. Imatralla 1986 saman kokoluokan tontilla pienehkö omakotitalo voitti yleisöäänestyksen! Pienille tonteille tarkoitettu talotyypistö kehittyi myös, esimerkkinä muun muassa Lahdessa 1978 esitelty ryhmä L-taloja.

Myös kaikki runkomateriaalit ovat olleet messutalojen myötä esillä. Lisäksi voi erikoisuuksina mainita yksittäisinä esimerkkeinä savitalon, olkitalon, vaneritalon, terästalon, lasitalon ja USA:sta asti tuodut Mobile Home-talot.

On selvää, että omakotitalojen yksilöllisyys ja erikoisuudet vaikuttavat ulkoasuun. Messualueilla yhtenäisen miljöökuvan aikaansaamiseksi on rakennukset yleensäkin ryhmitetty talotyypeittäin. Varsin usein omakotitaloja koskien esimerkiksi asuntokaduittain on katteen väri yhtenäistetty ja/tai julkisivuvärit annettu. Hieno esimerkki keinojen käytöstä on Pietarsaaren 1994 Australiakatu, jossa annettiin kate- ja julkisivuvärit sekä niihin sopivan kauniin ja kohtuuhintaisen kadunvarsiaidan suunnitelma ja rakentamisvelvoite. Yhtenäisyyttä on toki lisätty myös kunnallistekniikan keinoin. Napapiirin 1998 
alueen tilaustyönä tehdyt Tuulentuiverrus-valaisinpylväät luovat yhtenäisyyden lisäksi myös identiteettiä.

Yhtiömuodostaan johtuen rivitalokohteet ovat olleet enimmäkseen rakennusalan ja kuntien kiinnostuksen kohteina. Selvästi rivitaloluonteiset messualueet ovat muun muassa Kerava 1974, Hämeenlinna, Kokkola ja Pori 1975, Helsinki 1981, sekä uudemmista Espoo 2006. Muita rivitalokohteita on ollut 1985 Jyväskylässä, jossa esiteltiin yhteisöllisen asumisen pioneeriratkaisuja. Tornion 1987 messuille tehtiin ruotsalaista markbostad-asumista soveltanut yhtiö, rivi- ja kerrostalon välimuoto. Varkauden 1991 Laguuna-korttelin rivitaloissa näyttävyys, vaatimattomuus ja tehokkuus yhdistyvät hienolla tavalla. Tuusulassa 2000 Puusta rakennetut asuinkorttelit-kilpailun kautta ja valtakunnallisen "Moderni puukaupunki"-kärkihankkeina toteutetettiin myös kolme yhtiötä.

\section{Asuntomessujen kerrostalot}

On luontevaa, että asuntomessuilla pyritään sopivan monipuoliseen asunto/ hallintamuoto/rahoitus -palettiin alueittain. Näin on tapahtunutkin kerrostalojen myötä asukasluvultaan suurimmilla tai laajemman alueen avaavilla messualueilla. Näistä esimerkkeinä ovat Jyväskylä 1985 ja Turku 1988. Ne ovat saaneet myös alueille muuttaneiden asukkaiden palautetutkimuksissa parhaat pisteet.

Muista messuista poikkeava on Lahti 1993, jolloin syvän laman vuoksi Paavolan messualue oli kaupungin keskustassa ja toteutettiin kerrostaloilla ja arava-rahoituksella. Asuntoja oli kylläkin ennätysmäärä: 390 kappaletta. Yksi kohde käsitti aravakohteille poikkeuksellisesti kattoterassiasuntoja ja pihakannen alaisen pysäköinnin. Lisäksi toteutui laadukas ja jatkossakin hyvin kysytty palvelutalo vanhuksille uudenaikaisin dementikko-osastoin. Arkkitehtikilpailua kehittämiskeinona käytettiin kaikissa edellä mainituissa kohteissa. Turussa kilpailu oli pohjoismainen "talvikaupunki"-teemalla, joka toteutui suojaisten, valoisien ja puolilämpimien yhteistilojen sekä asuntoparvekkeiden myötä.

Asuntomessuilla edellä todetun lisäksi on saatu aikaan hyviä avauksia, muun muassa Jyväskylän 1985 rinnemaastoon terassoitu aravakerrostalo, jossa kaikkiin 43 asuntoon on oma sisäänkäynti. Kohde valittiin ainoana Helsingin ulkopuolisena kerrostalona Suomi rakentaa-näyttelyyn. Tampereen 1990 terästornitalo, Suomen ensimmäinen lajissaan, sisälsi rohkeaa arkkitehtuuria ja uutta varustelua, muun muassa asuntokohtaisen ilmastoinnin jäähdytyksineen. Uutta oli myös 3 metrin kerroskorkeus paljon ennen sen säätänyttä viranomaismääräystä. Ylöjärven 1996 modernit puukerrostalot olivat Suomen ensimmäiset. Tampereen TKK testasi niissä ennakkoon palo- ja äänieristyksen toteutumisen. 
Messuilla myös peruskorjaus, erityisasuminen

ja kestävä kehitys esillä

Erilaisia erityisteemoja on esitelty usein sekä messualueilla että etenkin oheiskohteissa, jolloin suuren yleisön sijasta on ajateltu alan ammattilaisia ja kuntaryhmiä. Peruskorjauksen varhainen esimerkki on Kokkolan 1975 vanhankaupungin kaksi taloa. Kohdevalinta ratkaisi vanhankaupungin säilymisen. Aluekorjauksina ja samalla messujen pääteemana on mainittava Kuusankosken 1983 Itä-Naukion ja Imatran 1986 Niskalammen messualueet. Molemmissa oli myös miljööseen sopivaa täydennysrakentamista. Keskeinen messuteema Tampereella 1990 oli vanhan teollisuusrakennuksen peruskorjaus ja käyttötarkoituksen muutos asunnoiksi.

Erityisasumisen saralta on moninaisia esimerkkejä: opiskelija- ja nuorisoasuntoja, ateljeetaloja, vammaisille rätälöityjä taloja ja asuntoja, palvelutaloja, vanhuksille ja veteraaneille tarkoitettuja sekä työtiloineen käsityöläisille räätälöityjä asuntoja. Useina erilliskohteina on toteutettu myös maatilan päärakennuksia ja kertaalleen tilanteeseen sopien jopa luonnonmukaista saaristokylärakentamista. Lisäksi "Laitoksista koteja"-ohjelman osana toteutettiin Napapiirin asuntomessuilla 1998 vanhan sairaalan ja puukkotehtaan muuttaminen asunnoiksi ja uusiksi loma-asunnoiksi Pyhä-Luostolla. Loma-asuminen tuli sitten vuonna 2000 omaksi messutyypikseen: ensimmäinen tapahtuma järjestettiin kaksiviikkoisena Ähtärissä ja keräsi 57000 kävijää. Yksittäinen erillishanke oli Espoon Puolarmaarin yhdessä kaupungin ja Puutarhaliiton kanssa järjestetty vapaa-ajan asumisen ja viherrakentamisen "Puutarha-asuminen' 92 "-näyttely. Siellä toteutettiin siirtolapuutarhahenkiset 32 mökkiä sekä 12 mallipihaa.

Ekologiateema tuli kansan tietoon ensimmäisen kerran jo Vantaan 1977 Ekotalon myötä. "Aurinkotaloja" puolestaan esiteltiin Kuopiossa 1980 ja osana kansainvälistä tutkimusta tehtiin IEA5-talo Pietarsaaressa 1994. Kestävä kehitys asuntomessujen yhtenä linjana tuli esille viimeistään Mäntsälässä 1992, jolloin tutkittiin ja kehitettiin jätehuoltoratkaisuja jätelain mukaisina jo ennen lain voimaantuloa. Ylöjärvellä 1996 messukohde oli mukana VTT:n ja Motivan tutkimuksessa, jossa energian kulutusennustelaskennan ja kulutuksen seurannan jälkeen kehitettiin energiatodistusjärjestelmää. Ylöjärvellä oli myös Ekoinfo ry:n kokoama uutuusesittely ekokeksinnöistä.

Käytännön tason merkittävä ympäristöteko on etenkin Tuusulan 2000 asuntomessujen toteutus entisen soranottoalueen maisemoimiseksi uudeksi asuntoalueeksi siten, että samalla rakenneratkaisuin suojeltiin alueen pohjavesi. Toteutuksen pohjaksi piti järjestää uudentyyppinen ympäristö- ja viherrakentamisen kilpailu. Pintavesien kulun, viemäritiiveyden, aluelämmityksen 
ja istutusalueiden lannoituksen osalta vaadittiin erityisratkaisuja. Messualue sai kunniaa vuoden 2000 ympäristörakenne-kilpailussa.

\section{Lopuksi}

Asuntomessutapahtuma saavutti Tuusulassa 2000 tähänastisen yleisöennätyksensä, noin 271000 kävijää. Toiminta on edelleen jatkunut vakaasti osoittaen tarpeellisuutensa. Yhdyskuntasuunnittelun ja asuntopolitiikan osalta asuntomessujen myötä heräävä julkinen keskustelu on jatkuvasti hyvin hyödyllistä. Käytössä ja kehitteillä on uusia variaatioita messutoimintaan. Niistä sekä lähivuosien suunnitelmista ja ohjelmista saa tietoa Asuntomessuilta (http:// asuntomessut.fi/).

Tiedossani ei ole, että suomalaisia asuntomessuja vastaavaa, jatkuvaa toimintaa olisi missään päin muualla maailmassa. Asuntomessut ovat suomalaisen asumisen "kansankorkeakoulu", asuntosuunnittelun ja kehittämisrakentamisen foorumi ja omaleimainen merkkituote.

Kirjoittaja toimi Suomen Asuntomessujen toimitusjohtajana vuosina 1977-2001, jolloin messuille rakennettiin yhteensä yli 3200 asuntoa ja messuvieraita oli yhteensä yli neljä miljoonaa.

KIRJALLISUUS

Kuoppamäki, Erkki \& Salmi, Juha (toim.) (2001). Asuntomessut 1970-2000, Ajankuvia \& Suuntalinjoja.

Suomen Asuntomessut. 